\title{
Treatment Strategy of Transarterial Chemoembolization for Hepatocellular Carcinoma
}

\author{
Shiro Miyayama \\ Department of Diagnostic Radiology, Fukui-ken Saiseikai Hospital, Fukui 918-8503, Japan; \\ s-miyayama@fukui.saiseikai.or.jp; Tel.: +81-776-23-1111
}

Received: 29 August 2020; Accepted: 13 October 2020; Published: 20 October 2020

\begin{abstract}
Transarterial chemoembolization (TACE) is a first-line treatment for patients with hepatocellular carcinoma (HCC) in Barcelona Clinic Liver Cancer stage B (BCLC-B). There are two major techniques of TACE: conventional TACE (CTACE) using iodized oil and gelatin sponge particles, and TACE using drug-eluting beads (DEB-TACE). The latest randomized controlled trial proved the superiority of cTACE regarding local effects over DEB-TACE; however, cTACE also damages the liver more severely. Therefore, cTACE should be performed for localized HCCs as selectively as possible. On the other hand, DEB-TACE has less liver toxicity and is favorable for patients with an advanced age, large and/or bilobar tumors, or a poor liver function. However, some BCLC-B HCCs are TACE-resistant and the concept of TACE unsuitability (mainly up-to-7 criteria out) has been proposed by Asia-Pacific Primary Liver Cancer Expert Meeting. Systemic therapy is recommended for patients with TACE-unsuitable HCC; however, the condition of TACE-unsuitable HCC does not always rule out TACE monotherapy and some up-to-7 criteria out tumors may also be good candidates for superselective cTACE when localized in limited liver segments. The sequential therapy of an antiangiogenic and TACE is also a novel option for patients with TACE-unsuitable HCC, antiangiogenic-refractory HCC, or even down-staged HCC.
\end{abstract}

Keywords: hepatocellular carcinoma; transarterial chemoembolization; iodized oil; gelatin sponge particle; drug-eluting bead; chemotherapeutic; systemic therapy; antiangiogenic; treatment strategy

\section{Introduction}

Since the first report by Yamada et al. [1], transarterial chemoembolization (TACE) has been widely performed for inoperable hepatocellular carcinoma (HCC). In 2002, two randomized controlled trials (RCT) demonstrated that TACE for inoperable HCC showed a survival benefit compared with best supportive care (BSC) [2,3]. Two meta-analyses also proved the clinical usefulness of TACE in prolonging HCC patients' survival [4,5]. Therefore, TACE has been recognized as an effective treatment option for inoperable HCC worldwide, and as a first-line treatment for HCC in Barcelona Clinic Liver Cancer stage B (BCLC-B) (Figure 1) [6].

Now, two major techniques of TACE have been performed: conventional TACE (cTACE) with iodized oil (Lipiodol 480, Guerbet Japan, Tokyo, Japan) and gelatin sponge (GS) particles; and TACE with drug-eluting beads (DEB-TACE). cTACE has been mainly developed in Asian regions, whereas DEB-TACE has been focused in Western countries. The concepts and rationales for both techniques, as well as adverse effects, are quite different; therefore, we should use them appropriately according to the patient and tumor condition. Thus, the purpose of this article is to describe the TACE strategy for BCLC-B HCC, mainly based on the conceptualistic position and techniques of TACE treatment in Japan. 


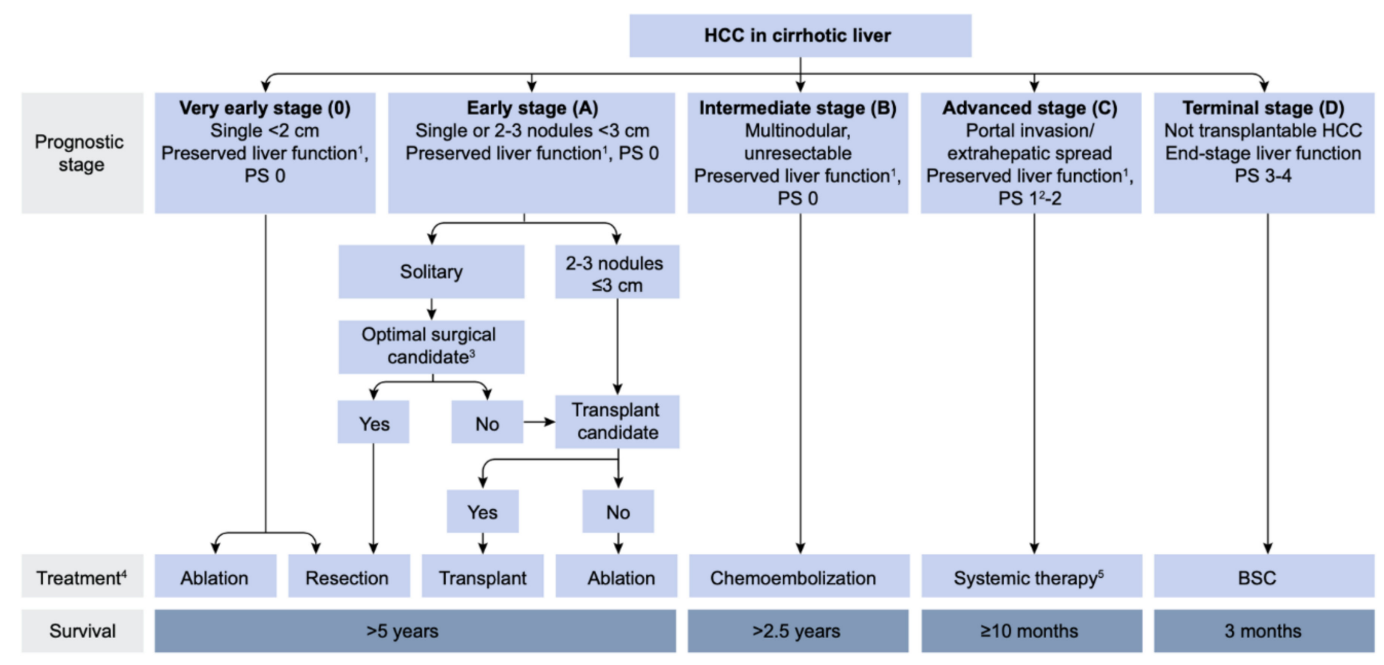

Figure 1. European Association for the Study of the Liver (EASL) clinical practice guidelines 2018 on hepatocellular carcinoma. Reprinted with permission from Ref. [6]. Abbreviations: PS, performance status; BSC, best supportive care.

\section{Hemodynamics in the Liver and HCC}

Understanding of the hemodynamics in the liver and HCC is very important to perform TACE procedures safely and effectively.

\subsection{Microvasculature of the Normal Liver}

Two major branches are arising from the terminal hepatic artery: one terminates within the portal tract supplying the bile duct (peribiliary vascular plexus: PBP), portal tract interstitium, and portal vein wall (portal vein vasa vasorum); and the other one penetrates the liver parenchyma unaccompanied by the portal vein or bile duct, named the isolated artery [7]. Most terminal hepatic arterioles connect with the PBP, and blood from the PBP directly drains into the portal venules and hepatic sinusoids. Therefore, bile duct injury can develop following TACE when the PBP is severely damaged [8]. The incidences of bile duct injury are usually high in the normal liver compared with the cirrhotic liver because the PBP is more hypertrophied in the cirrhotic liver [9]. The isolated artery communicates with the hepatic capsular arterial plexus, as well as with extrahepatic arteries, such as the internal mammary and inferior phrenic arteries, through the ligaments in the bare area of the liver. This communication can help the tumor mainly in the bare area of the liver to survive after TACE [10]. The intersegmental collateral formation between different segmental arteries can also develop following TACE and promote the tumor recurrence.

The normal liver parenchyma is supplied by a dual blood supply, including the portal venous system and the hepatic arterial system; thus, embolization of the hepatic artery can theoretically achieve selective ischemic necrosis of the tumor tissues alone. However, hepatic necrosis can also develop when superselective CTACE is performed [11-13].

\subsection{Hemodynamics in Hypervascular HCC}

Hemodynamics in the hepatocytic nodules can change according to the grades of malignancy of the nodules. During multistep hepatocarcinogenesis, the intranodular arterial supply initially decreases, but then acutely increases because of the increase in abnormal arterial supply. On the other hand, the intranodular portal supply gradually decreases, and finally disappears in moderately to poorly differentiated HCC tissue [14]. Therefore, overt HCC is predominantly supplied by arterial blood; however, some tumor tissues are still partially supplied by portal blood, such as well-differentiated tumor portions and tumors invading the surrounding liver through the capsule (capsular/extracapsular invasion) mainly located in the periphery of the tumor, as well as microsatellite lesions [15]. 
Simultaneously, the hepatic veins surrounding HCC are also occluded by tumor invasion and the tumor blood drains into the peritumoral area through the portal vein remnant in the capsule, depicted as corona enhancement on computed tomography (CT) during hepatic arteriography (CTHA) [16,17].

\section{Limitation of TACE and Necessity of Curative TACE}

\subsection{Limitation of TACE}

As mentioned above, well-differentiated tumor portions, capsular and/or extracapsular tumor invasions, and microsatellites are usually supplied by a dual blood supply; therefore, they can survive after simple embolization of the arterial side, particularly when it is performed non-selectively $[15,18]$. Additionally, there are two possible causes of local tumor recurrence after TACE. One important cause is portal blood supply to tumors via the portal venules and surrounding hepatic sinusoids due to the reversal of portal flow through the tumor drainage appearing during blockage of the hepatic arterial flow $[18,19]$. The other cause is arterial collateral supply to tumors from the neighboring arteries, sometimes from the extrahepatic arteries through the communication between the hepatic capsular arterial plexus and isolated artery [10].

\subsection{Necessity of Curative TACE}

TACE is recognized as a palliative treatment option for HCC; however, it is reported that a complete response (CR) after the initial TACE is the most robust predictor of long-term survival [20]. In other words, ineffective TACE may shorten a patient's lifespan. TACE loads hypoxic and chemotherapeutic stress on HCC, and some surviving tumors frequently change to more aggressive and TACE-resistant tumor tissues, such as sarcomatous appearances or mixed hepatocholangiocellular phenotypes [21,22]. Hypoxia induced by TACE also stimulates vascular endothelial growth factor (VEGF) production by the residual tumor cells, which can promote the tumor progression following TACE [23,24]. Furthermore, some surviving tumors can be nourished by the portal venous system if the arterial branches are markedly attenuated by TACE and extrahepatic collaterals cannot develop [25]. These suggest that ineffective TACE can also produce uncontrollable tumors. In our recent analysis, the incidences of intrahepatic distant recurrence (IDR) of HCC in patients with local tumor progression (LTP) were significantly higher than in patients without LTP $(p=0.0004)$ [26]. This indicates that some IDR may be associated with LTP: metastases may be from locally progressed tumors or may be from newly developed tumors promoted mainly by high expression of VEGF production from the viable tumor cells. In addition, TACE damages the liver and bile ducts $[8,27,28]$ (Figure 2). Therefore, it is important to perform curative TACE when the tumor is localized and controllable.

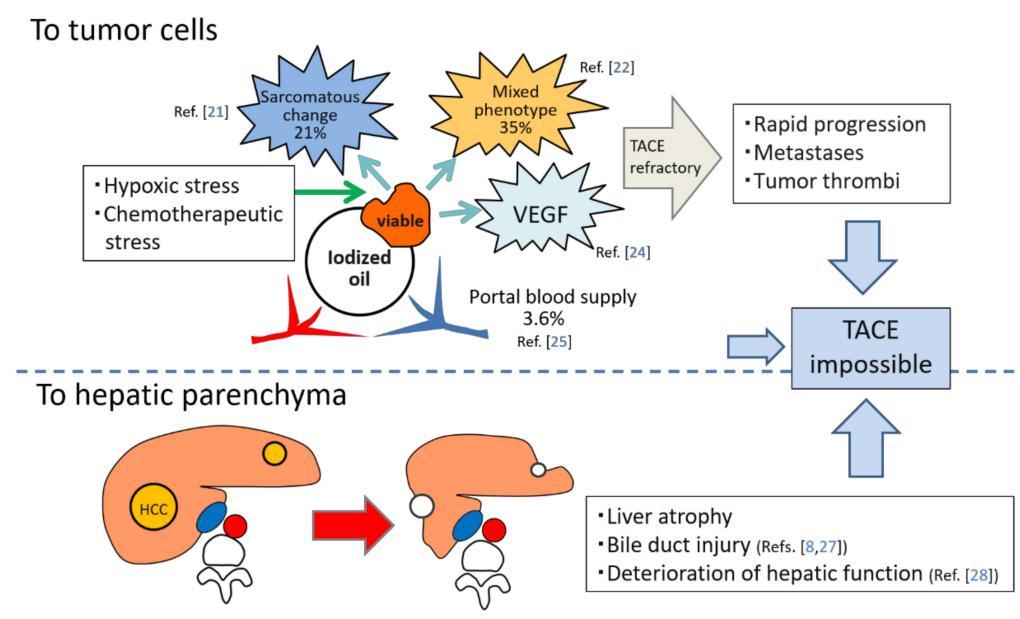

Figure 2. Schematic representation of negative aspects of TACE. Abbreviations: VEGF, vascular endothelial growth factor. 


\section{Rationale for Each TACE Technique}

\subsection{Rationale for Bland Embolization and DEB-TACE}

Various kinds of microspheres are available. Experimental studies show that smaller-sized microspheres induce more necrosis of the hepatic parenchyma. Doxorubicin-loaded DEBs can also cause a coagulative necrosis of the adjacent liver parenchyma; therefore, smaller-sized DEBs induce more marked necrosis of the hepatic parenchyma than the same-sized bland beads or larger-sized DEBs [29]. For tumor tissues, smaller DEBs are likely to occlude distal tumor vessels, resulting in more localized chemotherapeutic delivery and a good imaging response [30], although the risk of unexpected complications, such as biliary necrosis and systemic embolization, may increase [28,31,32]. However, one of the important technical problems of particle embolization is that microspheres cannot embolize the tumor drainage. Therefore, the reversed flow from the surrounding hepatic sinusoids and portal venules into the peripheral tumor portion following arterial blockage cannot be blocked. Micro-arterial communications may also be unblockable. As a result, tumor tissues supplied not only by both arterial and portal blood but also by collateral blood including portal blood may survive mainly at the periphery (Figure 3) [33,34]. In DEB-TACE, it is expected that eluted chemotherapeutics may necrotize the surviving tumor cells; however, it is uncertain how the chemotherapeutics reach the viable tumors.
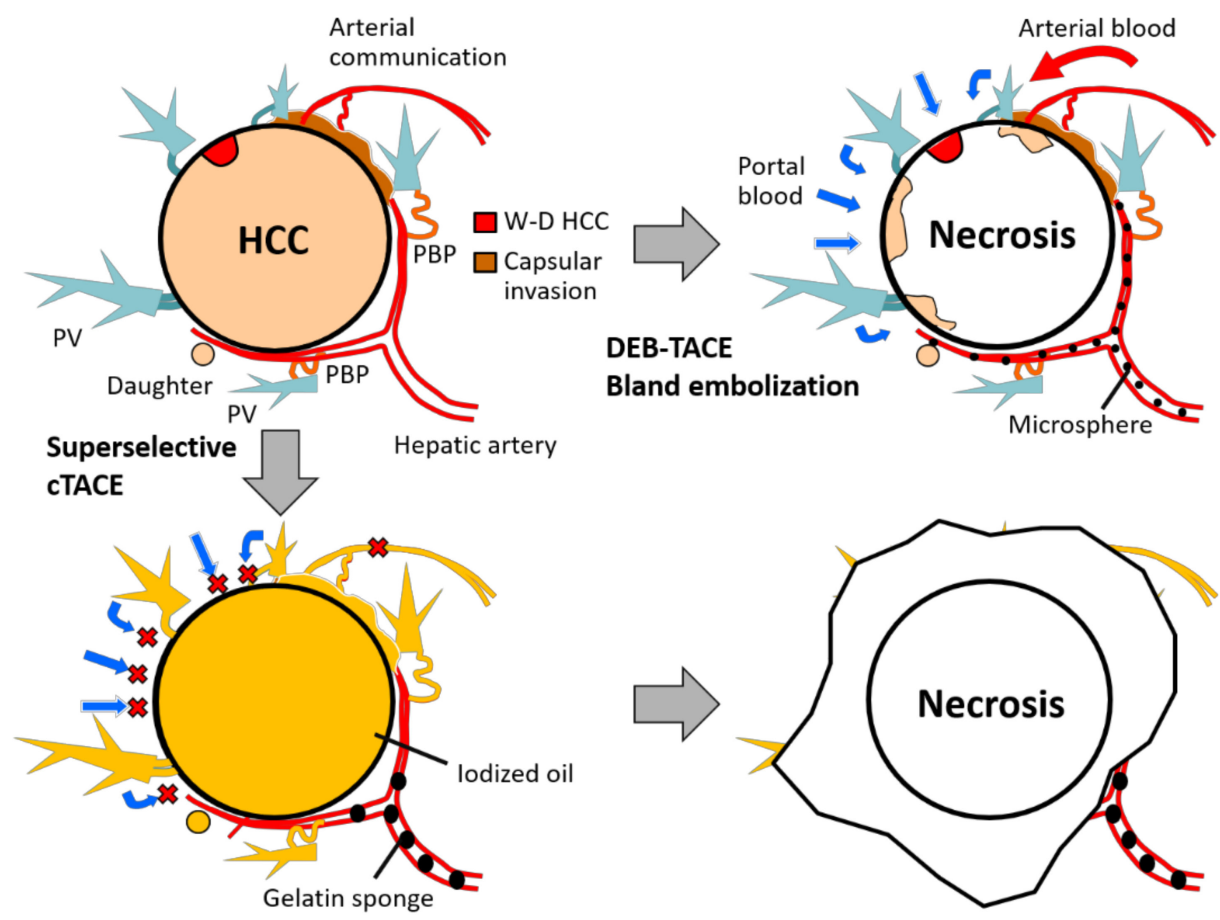

Figure 3. Schematic representation of rationale for superselective cTACE and DEB-TACE/bland embolization. Reproduced with permission from Ref. [33]. An Open Access article (CC BY 4.0). Abbreviations: W-D, well-differentiated; PBP, peribiliary vascular plexus, PV, portal vein.

In addition, DEB-TACE damages the hepatic artery more severely than cTACE (per branch, $p<0.001$ and per patient, $p=0.005$ ) [35] and the incidences of arterioportal shunt formation are also significantly higher following DEB-TACE than cTACE (48.7 vs. 8.1\%, respectively, $p<0.001)$ [36]. 


\subsection{Rationale for $C T A C E$}

Iodized oil is a semi-fluid embolic agent that can change its shape in vessels. Two types of iodized oil emulsion can be prepared: water-in-oil emulsion (WOE) and oil-in-water emulsion (OWE). WOE should be properly prepared because WOE has stronger embolic effects on tumor vessels than OWE $[37,38]$.

Iodized oil injected into the hepatic artery is initially retained in the tumor sinusoids. When more than a certain amount of iodized oil is pooled in the tumor sinusoids, some iodized oil overflows into the portal veins through the drainage route of the tumor [39,40]. Iodized oil also enters the portal veins through the PBP in the surrounding liver [40]. As a result, the peritumoral portal blood flow, including reversed portal blood flow into the tumor, can be temporarily blocked by viscosity of iodized oil. Moreover, some iodized oil can pass through the arterial communications and reach the neighboring hepatic arterial branches and/or extrahepatic arteries $[10,13,41]$. This allows embolization or identification of an occult tumor feeder and may prevent the arterial collateral supply to the tumor following TACE [13]. By adding arterial blockage with GS particles after injection of iodized oil, both the hepatic artery and portal vein surrounding the tumor can be embolized (Figure 3). Small-sized GS particles (slurry, approximately $0.2-0.5 \mathrm{~mm}$ in diameter) are favorable to achieve more necrosis because the reported mean diameter of tumor feeders in tumors of 7 to $63 \mathrm{~mm}$ (mean, 20.3 \pm 12.7 ) in diameter was $0.41 \pm 0.32 \mathrm{~mm}$ (range, $0.12-1.79$ ) [42]. This leads not only to ischemic necrosis of the hypervascular tumor portions but also to peritumoral necrosis including tumor portions supplied by a dual blood supply and induces shrinkage of the surrounding liver parenchyma [11-13,33,40,43]. This also indicates that CTACE damages the normal liver; therefore, selective catheterization is essential to minimize the liver toxicity. It is also important to minimize the total dose of iodized oil, and the maximum dose in one cTACE procedure is generally $10 \mathrm{~mL}$ in Japan and $15 \mathrm{~mL}$ in Western countries [44].

\subsection{Therapeutic Effects of Bland Embolization with Particles}

In the recent RCT conducted by Malagari et al. [45], TACE using doxorubicin-loaded DEB presented a better local response, fewer recurrences, and a longer time to progression than bland embolization with same-sized microspheres $(p=0.008)$. However, no significant benefit to survival of DEB-TACE was found, partly because of a short follow-up. On the other hand, the latest RCT conducted by Brown et al. [46] showed no significant differences in tumor response $(p=0.48)$, median progression-free survival $(p=0.11)$, and overall survival $(p=0.64)$ between the bland embolization and doxorubicin-loaded DEB-TACE groups.

It is obvious that bland embolization has lesser damage to the liver than CTACE and DEB-TACE because non-drug-loaded microspheres can occlude the vessels with mild foreign body reaction [47], mostly non-necrotic vascular changes without hepatic necrosis [29]. However, the role of bland embolization with microspheres has not yet been established in the treatment strategy for HCC. In a report by Osuga et al. [48], the 1- and 2-year survival rates of 59 naïve HCC patients with a mean largest tumor diameter of $4 \mathrm{~cm}$ (range, 1.2-14.7 cm) treated with bland embolization using HepaSphere (Merit Medical, Jordan, UT, USA) of 53 to $212 \mu \mathrm{m}$ in a dry state were $100 \%$ and $83 \%$, respectively, and the median survival time (MST) was 30 months. Maluccio et al. [32] reported the outcomes of bland embolization with small particles (50- $\mu \mathrm{m}$ polyvinyl alcohol particles and $40-120-\mu \mathrm{m}$ Embosphere (Merit Medical) for 322 HCC patients. Among them, 109 patients without portal vein invasion or extrahepatic disease had an MST of 40 months and 1-, 2-, and 3-year survival rates of $84 \%, 66 \%$, and $51 \%$, respectively. However, four patients died of acute hepatic failure and two died of pulmonary embolism. Small particles have strong therapeutic effects because these can impart terminal vessel blockage within the tumor; however, the risk of unexpected complications caused by migrated particles may increase [31,32]. Therefore, a superselective approach and careful observation of pulmonary shunting is recommended in the use of small-sized particles. In a report by Lanza et al. [49], 40- or 100- $\mu \mathrm{m}$ Embozene (Varian, Austin, TX, USA) could be safely used in the superselective bland embolization procedure. 
Bland embolization with gelatin sponge particles can also be effective for achieving hemostasis of ruptured HCC in patients in a hemodynamically unstable condition with minimal invasiveness [50].

\subsection{Proper Use of Chemotherapeutics in TACE}

One to three chemotherapeutics are usually used in TACE, although the necessity of chemotherapeutics is still controversial [3-5,45,46].

CTACE has a long history in Japan; however, the most effective and least toxic regime for CTACE has not yet been established. Some retrospective studies showed the superiority of cisplatin over doxorubicin/epirubicin in terms of overall survival [51-53], although a prospective study showed no significant differences [54]. However, cisplatin requires pre- and post-hydration because of its renal toxicity and also has severe side effects, including thrombocytopenia, hepatic failure, and hypersensitivity reactions. The incidence of hypersensitivity reactions increases when the number of treatment cycles using cisplatin is increased [55]. Therefore, cisplatin is mainly used for doxorubicin/epirubicin refractory tumors and/or advanced tumors [56]. Miriplatin is a lipophilic platinum chemotherapeutic that is available only in Japan. It has less toxicity; however, the RCT showed no significant differences in therapeutic efficacies over epirubicin [57]. Some retrospective studies also showed a significantly higher local recurrence rate in the miriplatin TACE group compared with the epirubicin/epirubicin plus mitomycin C TACE group [58,59]. Very slow release of active platinum (5.9\% at 28 days) and less damage to the artery are considered to be the main causes of high frequent local tumor recurrence [58]. Now, miriplatin is mainly used in balloon-occluded TACE because of its association with less arterial damage [60].

In the clinical setting, switching the chemotherapeutics may be a feasible option for advanced HCC, especially when the tumor becomes resistant to the initial form of CTACE, although there is not enough scientific evidence [54,56,57].

In DEB-TACE, DC Bead (Boston Scientific, Marlborough, MA, USA) and Embozene-Tandem (Varian) can load positively charged chemotherapeutics, such as doxorubicin or epirubicin. HepaSphere (Merit Medical) can also load cisplatin by its reservoir effect, besides positively charged chemotherapeutics, but it is released within $24 \mathrm{~h}$ [61]. No comparisons are available of the long-term prognosis after DEB-TACE between each embolic agent, because of the heterogeneity in patient selection, etiology of the underlying cirrhosis, embolization technique and particle size, and relatively short-term follow-up.

\subsection{Comparison of Therapeutic Effects between DEB-TACE and cTACE}

Table 1 shows the results of RCT studies regarding therapeutic effects between DEB-TACE and CTACE. Three RCTs conducted in Europe showed no significant differences in local tumor control and/or survival between the DEB-TACE and cTACE groups [62-64]. Supplementary analyses of the PRECISON V study showed that in $67 \%$ of patients with more advanced disease (Child-Pugh B class, Eastern Cooperative Oncology Group [ECOG] performance status 1, bilobar, or recurrent disease), the incidences of an objective response and disease control were significantly higher in the DEB-TACE than cTACE group ( $p=0.038$ and $p=0.026$, respectively) [62]. Regarding the systemic side effects of doxorubicin, such as alopecia, skin discoloration, mucositis, and bone marrow suppression, there was a significant benefit of DEB-TACE over CTACE $(p=0.012)$ [62]. In the PRECISON Italia study, postprocedural pain was more frequent and severe after CTACE $(p<0.001)$ [64]. 
Table 1. Comparison of therapeutic effects between DEB-TACE and cTACE.

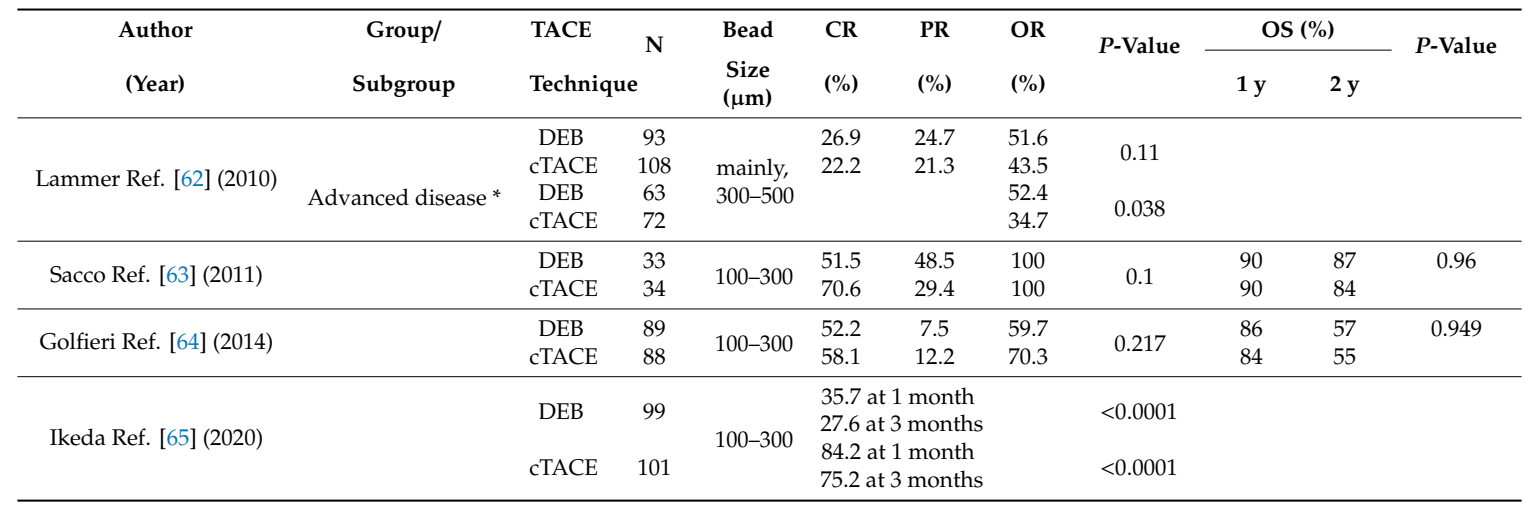

* At least, one of Child-Pugh B, ECOG 1, recurrent disease, bilobar disease was present. Abbreviations: CR, complete response; PR, partial response; OR, objective response; OS, overall survival.

On the other hand, the latest RCT conducted in Japan proved significant differences in CR rates between CTACE and DEB-TACE groups ( 84.2 vs. $35.7 \%$ at 1 month and 75.2 vs. $27.6 \%$ at 3 months, respectively [both $p<0.0001$ ]), although the rates of grade $3-4$ of elevation of serum aspartate aminotransferase and alanine aminotransferase were significantly higher in the cTACE group (48.5 vs. $5.1 \%$ and 38.7 vs. $3.1 \%$, respectively [both $p<0.0001$ ]) [65]. This study indicates that CTACE can achieve complete tumor necrosis by sacrificing the surrounding liver, and the discrepancy of outcomes of cTACE between Europe and Japan might be caused by different devices and techniques because superselective CTACE using a smaller (1.5- to 2-F tip) microcatheter under intraprocedural monitoring by CT or cone-beam CT (CBCT) is a standard technique in Japan [13]. This study did not evaluate the survival benefit of superselective cTACE over DEB-TACE because of a short follow-up period; however, it is expected the extension of the patient's lifespan in the cTACE group, because a CR after the initial TACE is the most significant prognostic factor in HCC patients [20].

Theoretically and clinically, liver toxicity of DEB-TACE is mild compared with cTACE $[62,64]$ because of a lower dose of active chemotherapeutics and proximal embolization for liver and tumors, although sudden death caused by systemic embolization infrequently develops $[31,32]$ and the rate of biliary complication is significantly higher compared with that of cTACE (36.8 vs. $14.4 \%$, respectively, $p<0.001$ ) [28]. Therefore, DEB-TACE is favorable for patients with an advanced age, large and/or bilobar tumors, or a poor liver function. On the other hand, cTACE should be indicated for patients with localized tumors and a preserved liver function. Adverse effects of bland embolization with microspheres are milder than those of DEB-TACE [47]; therefore, it is suitable for elderly patients with large HCCs, Child-Pugh score 9 patients, or patients with ruptured HCC.

\subsection{Technical Advantages of Selective cTACE Compared with Non-Selective cTACE}

Non-selective cTACE using a large volume of iodized oil is not only less effective for tumors but also more harmful for normal liver parenchyma; therefore, catheter position is very important to reduce the total dose of iodized oil and minimize the liver damage. CTACE also damages the hepatic artery by arteritis due to chemotherapeutics and allergic reaction to gelatin [66,67], and attenuation of the hepatic arterial circulation reduces the hepatic function and causes the extrahepatic collaterals to develop $[68,69]$. Therefore, damage to the hepatic artery by CTACE should be minimized so as to preserve the liver function and prolong the duration of TACE treatment. Generally, selective cTACE is defined as CTACE at the segmental hepatic artery, whereas superselective CTACE is defined as CTACE at the subsegmental hepatic artery. CTACE at the most distal level of the subsubsegmental hepatic artery is termed ultraselective cTACE $[13,40]$. 
Most microsatellite lesions, which are usually non-selective cTACE-resistant [15], are located in the corona enhancement area [70]. The corona area should be included in the treatment area because cancer cells first enter there before forming distant metastatic lesions. However, the width of the corona is not uniform and is thick in places [17]; therefore, the safety margin should be normally determined individually before curative treatment, such as for hepatic resection or radiofrequency ablation (RFA), based on CTHA findings [70]. In TACE, we conveniently determine the safety margin according to the tumor size: at least $5 \mathrm{~mm}$ wide for tumors $<25 \mathrm{~mm}$ and $10 \mathrm{~mm}$ wide for tumors $\geq 25 \mathrm{~mm}$, corresponding to the width of corona enhancement [26,71,72] based on a histological study [73]. As mentioned above, superselective cTACE can simultaneously treat the drainage area in most tumors because the corona area is usually supplied by the tumor feeder [39]; however, in some cases, a part of the corona area is supplied by another arterial branch. In such cases, the arterial branch should be subsequently embolized, although iodized oil has already been distributed there via the portal vein connecting with tumor drainage.

\section{Technical Tips for Performing Effective Superselective cTACE}

\subsection{Achievement of Marked Portal Vein Visualization with Iodized Oil During cTACE}

There is a relationship between the grades of portal vein visualization with iodized oil and local tumor recurrence. We divided the grades of portal vein visualization with iodized oil into three grades on spot radiographs obtained during the procedure: grade 0 , no visualization; grade 1 , visualization adjacent to the tumor; and grade 2, visualization in the whole or extended embolized area, and the local recurrence rates in the grade 2 group were significantly lower than those in the grades 1 and 0 groups ( $p<0.0485$ and $p<0.0001$, respectively) (Figure 4) [40].
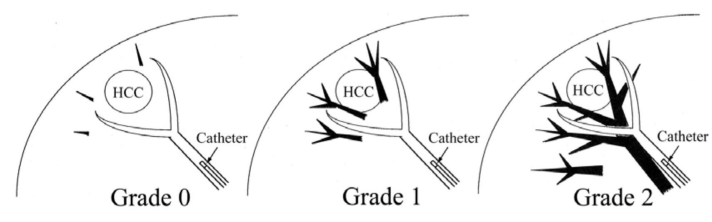

(a)

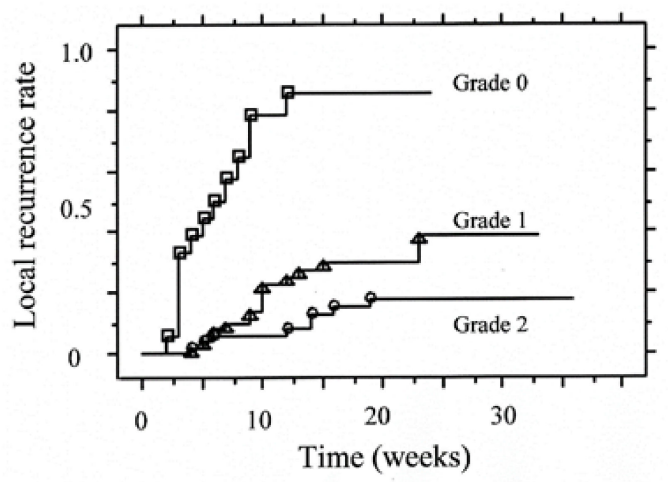

(b)

Figure 4. Classification of grades of portal vein visualization with iodized oil and relationship between local tumor recurrence. (a) Schematic representation of grades of portal vein visualization with iodized oil; (b) Graph shows the local recurrence rates calculated with the Kaplan-Meier method for each portal vein visualization group. The local recurrence rates for tumors in the grade 2 group were significantly lower than those for tumors in the grades 1 and 0 groups ( $p=0.0485$ and $p<0.0001$, respectively). The local recurrence rates for tumors in the grade 1 group were also significantly lower than those in the grade 0 group $(p<0.0001)$. Reprinted with permission from Ref. [40].

In superselective cTACE, iodized oil should be slowly injected to avoid "oil cast formation" in the arteries. The endpoint of iodized oil injection is grade 1 portal vein visualization, not grade 2 , because iodized oil in the tumor and surrounding liver is pushed into the portal vein by GS slurry injection and widely distributes into the whole embolized area, and frequently beyond the embolized area. As a result, grade 2 visualization can be obtained [74]. When the flow of the tumor-feeding branch unexpectedly stops before adequate portal vein visualization, we can adopt two measures: injection of $0.5 \mu \mathrm{g}$ of prostaglandin $\mathrm{E} 1$ or $0.5 \mathrm{~mL}$ of $2 \%$ lidocaine through the catheter to increase 
arterial flow; and more distal advancement of a microcatheter to achieve a semi-wedged condition [74]. The latter technique should be attempted first, if possible, because it is usually more effective. When the microcatheter is advanced more distally, iodized oil can be re-injected. In such a condition, iodized oil can flow forward due to the injection force, because stretching the catheterized artery and the mass effect of the microcatheter itself can prevent backflow of iodized oil. As a result, the volume of iodized oil passing through the arterioportal and arterial communications can increase and embolic effects can be enhanced.

\subsection{Importance of the Order of Embolization of Each Tumor Feeder}

When multiple feeding branches are present, the order of embolization of each feeder is key to improve the therapeutic effect of cTACE. The main tumor feeder should be embolized last because dense retention of iodized oil and contrast material disturbs the depiction of the residual tumor stain and other small feeders on digital subtraction angiography performed immediately after cTACE. Additionally, embolic materials injected into the main tumor feeder are sometimes pushed back by the reversed flow through the minor tumor feeder when the flow of the main tumor feeder becomes near stasis [74]. In tumors partially fed by an extrahepatic collateral supply, the feeding branch of the extrahepatic artery should also be embolized first, if possible, because arterial blood flow to tumors through the extrahepatic artery immediately increases when the hepatic arterial flow is stopped [75]. Moreover, each tumor feeder should also be embolized from distal to proximal in order to avoid inadvertent occlusion of the distal tumor feeders with overflowing embolic materials during embolization of the proximal tumor feeder [74]. However, feeders that are considered difficult to catheterize, such as the caudate artery or tiny tumor feeders arising from extrahepatic arteries, should be embolized first, because the performance of a microcatheter-microwire system is gradually deteriorated during the procedure [74].

\subsection{Usefulness of Stepwise cTACE for Large HCCS}

CTACE is also widely performed for large HCCs; however, the previously reported 5-year overall survival rate was only $7-9.7 \%$ [76,77]. In addition, the use of a large volume of iodized oil for large tumors carries the risk of catastrophic complications, such as systemic embolization of the lung or brain [78,79] and acute tumor-lysis syndrome [80]. Therefore, we typically perform stepwise superselective cTACE for localized tumors $>7 \mathrm{~cm}[81,82]$. Two to three cTACE sessions are scheduled depending on the vascular anatomy, and each session is performed in a superselective fashion using $\leq 10 \mathrm{~mL}$ of iodized oil at 3- to 10-week intervals according to the patient and tumor conditions. In our recent analysis of 25 patients with HCC $\geq 10 \mathrm{~cm}$ (mean, $130 \pm 27.6 \mathrm{~mm}$ [range, 101-193], single [ $n=12$ ], $2-9$ [ $n=6$, mean, $4.2 \pm 2.6]$, and $\geq 10$ tumors $[n=7$, including 2 with $\geq 50$ tumors], with vascular invasion $[n=5]$ ), the 5 -year survival rate was $23.1 \%$, and that of patients with tumors $\leq 3$ lesions was $38.9 \%$ [82]. This indicates that cTACE is also effective for localized huge HCCs. However, cTACE of extrahepatic collateral arteries was required in $84 \%$ of patients during the treatment course [82]. Therefore, the outcomes of CTACE for huge HCC may be more strongly influenced by the TACE technique compared with cTACE for small HCC. Bland embolization with gelatin sponge particles followed by CTACE is another alternative option for huge HCC to safely embolize the tumor [83].

\subsection{Usefulness of CT/CBCT and TACE Guidance Software}

A unified CT and angiography system that has been developed in Japan can improve the technical success rate of superselective CTACE [84]. However, it is relatively expensive and is not widely distributed. $\mathrm{CBCT}$ is a new technology to obtain CT images using a flat panel detector of an angiography unit. It has been reported that $\mathrm{CBCT}$ can improve not only local tumor control but also the prognosis of HCC patients [71,85]. TACE guidance software, including automated tumor feeder detection (AFD), is also a novel software using CBCTHA data that can reduce the physician's workload and improve the treatment accuracy $[26,72,86-89]$. This software can provide 
useful information regarding the order of embolization and division of chemotherapeutics for each tumor feeder. The curability and invasiveness can also be controlled by changing the virtual target size including the safety margin. If curative TACE is expected, a wider safety margin should be created to embolize all potential tumor feeders. If palliative TACE is recommended, the safety margin should be narrower to reduce the adverse effects [90]. In our previous analysis of $155 \mathrm{HCCs} \leq 5 \mathrm{~cm}$ (mean diameter, $17.4 \pm 7.4 \mathrm{~mm}$ [range, 10-48]) including 18 angiographically occult tumors, AFD software using CBCTHA data could detect $85.4 \%$ of tumor-feeding subsubsegmental hepatic arteries, $90.3 \%$ in new tumors and $75.3 \%$ in recurrent tumors. Regarding the technical success, complete ultraselective cTACE could be performed in $82.6 \%$ of tumors [72].

AFD software can also be useful to identify a tumor feeder arising from extrahepatic arteries and expand the indication and safety of TACE through extrahepatic collaterals. However, if the tumors are fed by the cystic, gastric, or colonic artery, the safety margin should not be included in the target to avoid non-target embolization [90,91].

In our recent analysis, the 5-year survival rate of 102 patients with tumors $\leq 7 \mathrm{~cm}$ and $\leq 5$ lesions (mean largest tumor diameter, $25.3 \pm 12.3 \mathrm{~mm}$ [range, 6-69]; mean tumor number, $1.9 \pm 1.1$ [range, 1-5]) treated with superselective CTACE using TACE guidance software was $60 \%$, and about half $(13 / 27)$ of patients died of HCC-unrelated causes [26]. This indicates that TACE guidance software can prolong a patient's lifespan.

\section{Concept of TACE Unsuitability}

However, TACE-resistant HCCs are also present. In 2019, Asia-Pacific Primary Liver Cancer Expert (APPLE) Meeting proposed the concept of TACE unsuitability. TACE unsuitability is defined as each one of the following three clinical conditions that prevent a survival benefit from TACE or conditions that TACE is even harmful: (i) unlikely to respond to TACE: confluent multinodular type, massive or infiltrative type, simple nodular type with extranodular growth, poorly differentiated type, intrahepatic multiple disseminated nodules, or sarcomatous changes after TACE; (ii) likely to develop TACE failure/refractoriness: up to seven criteria out nodules; and (iii) likely to become Child-Pugh B or C class after TACE: up-to-7 criteria out nodules (especially, bilobar multifocal HCCs) or modified albumin bilirubin (ALBI) grade $2 b$ [92].

In patients with TACE-unsuitable HCC, systemic therapy is generally recommended. However, TACE-unsuitable HCC is not always contraindicated for TACE monotherapy. Because up-to-7 criteria out tumors include various tumor conditions, like BCLC-B HCC, and some up-to-7 criteria out tumors may also be good candidates for superselective CTACE when tumors are located in limited segments of the liver [92]. Complete necrosis can also be achieved in some confluent multinodular and simple nodular type with extranodular growth HCCs when a sufficient safety margin can be embolized. A recent report indicated that age $\geq 75$ years $(p=0.022), \operatorname{AFP} \geq 200 \mathrm{ng} / \mathrm{mL}(p=0.010)$, tumor counts $\geq 11$ $(p=0.008)$, and heterogenous enhancement $(p=0.024)$ were significant prognostic factors in BCLC-B HCC patients treated with superselective CTACE [93]. This indicates that TACE is also effective for some up-to-7 criteria out tumors. Therefore, the indication of TACE for unsuitable patients should be discussed according to the ability of TACE in own institution and a tailor-made treatment strategy is recommended. When TACE is performed first and the tumors may rapidly recur and/or the tumor features may change to unfavorable forms (such as hypovascular/ring-like enhancement, infiltrative tumors around the previously treated tumor that iodized oil is densely accumulated, hyperintensity on diffusion-weighted magnetic resonance imaging, and development of vascular invasion and/or lymph node metastases) following TACE, additional TACE should be abandoned and systemic therapy should be immediately stated.

The combination of an antiangiogenic and TACE is a promising treatment option for TACE-unsuitable HCC because pre-administration of an antiangiogenic can enhance the therapeutic effects of TACE considered to be facilitated by promoting vascular normalization and improving the distribution of iodized oil mixed with chemotherapeutics [94,95]. Therefore, TACE or hepatic arterial 
infusion chemotherapy should be promptly performed for patients with antiangiogenic-refractory HCC, if possible.

\section{TACE Strategy According to the Number and Size of HCC}

BCLC-B HCC includes various tumor conditions and the goal of TACE treatment is not only to control the tumors but also to maintain the liver function [92]. Therefore, it is essential to change the technique and magnitude of TACE in individual cases, although there is no consensus on how to change the TACE techniques according to the tumor spread.

In a report by Yamakado et al. [96], a patient subgroup with Child-Pugh A class and tumors $\leq 7 \mathrm{~cm}$ and $\leq 4$ lesions showed significantly favorable outcomes among BCLC-B HCC patients. The Child-Pugh score was also a significant prognostic factor, and the prognosis of Child-Pugh score 9 patients treated with cTACE was worse than that of the BSC group in the previous RCT [3,97]. Yamakado et al. [98] also reported that cTACE techniques has an impact on patient survival. In those with $\mathrm{HCC} \leq 7 \mathrm{~cm}$ and $\leq 5$ lesions, the prognosis of patients who underwent selective/superselective cTACE was significantly better than that of patients treated with non-selective CTACE $(p=0.033)$. These studies suggest that superselective cTACE is recommended for patients with Child-Pugh scores of 5-8 and HCC $\leq 7 \mathrm{~cm}$ and $\leq 5$ lesions.

Now, we perform cTACE for almost all HCC patients with Child-Pugh scores $\leq 8$ because it has a stronger therapeutic effect compared with other techniques. For tumors $\leq 7 \mathrm{~cm}$ and $\leq 3$ lesions, superselective cTACE, mainly ultraselective cTACE, is performed. For tumors $>7 \mathrm{~cm}$ but $\leq 3$ lesions, stepwise superselective cTACE is also performed with curative intent $[81,82]$. Bland embolization, DEB-TACE, or systemic therapy is another option, especially for elderly patients. Bland embolization followed by CTACE is also another option to safely embolize the huge tumor [83]. For bilobar multiple lesions $\geq 4$, superselective CTACE is not always indicated but the embolized area should be minimized to reduce liver toxicity. In this subgroup, DEB-TACE or systemic therapy is also an alternative option. For far advanced (large and bilobar) tumors, palliative cTACE, DEB-TACE, or bland embolization is indicated to aim at mass reduction or prevention of tumor rupture; however, systemic therapy is recommended first when the patient has a preserved hepatic function, although there is a risk of tumor bleeding in antiangiogenic therapy (Figure 5) [99]. In HCC patients with Child-Pugh score 9, DEB-TACE or bland embolization is recommended.

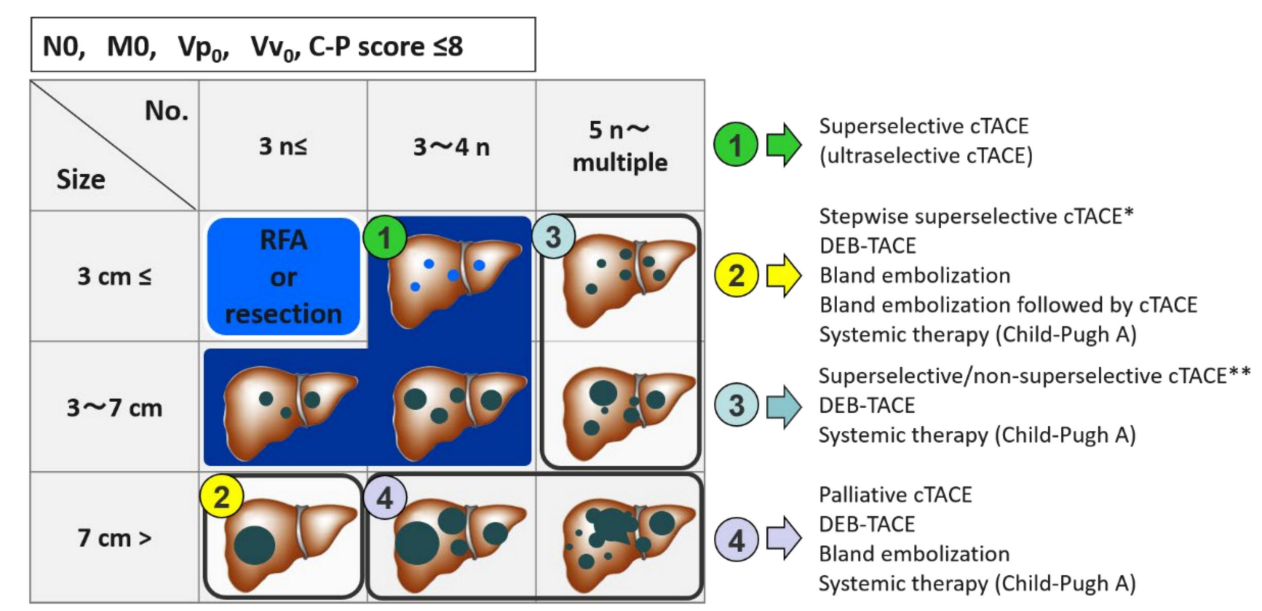

*Stepwise superselective TACE is recommended for $\mathrm{HCC}>7 \mathrm{~cm}$ to avoid systemic embolization and acute tumor-lysis syndrome (Refs. [81,82]).

**The embolized area should be minimized to reduce adverse effects.

DEB-TACE or bland embolization is recommended in HCC patients with Child-Pugh score 9.

Figure 5. Our TACE strategy according to the patient and tumor conditions. Abbreviation: C-P, Child-Pugh; $n$, number; RFA, radiofrequency ablation. 
According to APPLE Consensus Statements, tumors $\leq 6 \mathrm{~cm}$ and $\leq 6$ lesions are classified into the good response to cTACE subgroup, tumors $>6 \mathrm{~cm}$ and $\leq 6$ lesion and tumors $\geq 7$ lesions are classified into the poor response to CTACE subgroup. DEB-TACE and systemic therapy is another option for these tumor conditions (Figure 6) [92]. In particular, antiangiogenic therapy is recommended for TACE-unsuitable tumors. In addition, the sequential therapy of an antiangiogenic and TACE is a novel option for antiangiogenic-refractory HCCs or even for down-staged HCCs by antiangiogenic therapy [92].

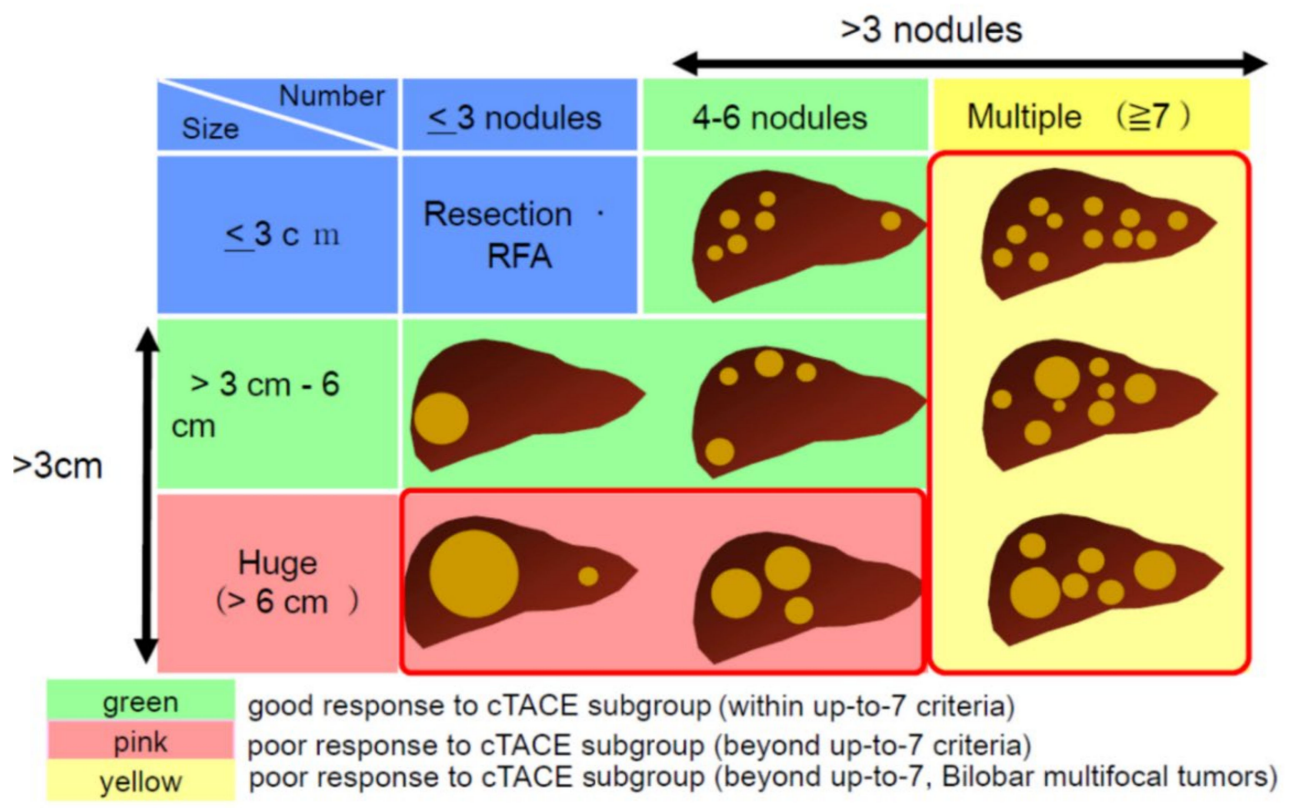

Figure 6. Heterogeneity of intermediate-stage HCC and grade of response to CTACE in each subgroup. Reproduced with permission from Ref. [92]. An Open Access article (CC BY 4.0).

\section{Further Directions}

With the potential of ultraselective cTACE to cure small HCC including hypovascular tumor portions [11-13,100], it can replace surgical resection and RFA in selected patients with BCLC 0-A HCC. In the eUpdated European Society of Medical Oncology (ESMO) guideline on hepatocellular carcinoma algorithm on 19 June 2020, indication of TACE has been expanded to BCLC 0-A HCC (Figure 7) [101]. This treatment strategy will become more popular, if TACE guidance software and a small-sized microcatheter system become widely available. Additionally, the sequential therapy of an antiangiogenic and TACE is a promising treatment strategy for BCLC-C HCC patients with a preserved hepatic function [102]. Indeed, in the fourth version of clinical practice guidelines for HCC proposed by the Japan Society of Hepatology in 2017, TACE has also been recommended for not only a solitary tumor $>3 \mathrm{~cm}$ but also tumors with vascular invasion, in addition to BCLC-B HCC [103]. We believe that TACE still plays an important role in the treatment of HCC patients. We should keep in mind that TACE is not a simple local chemotherapy, and the outcomes are markedly influenced by TACE techniques. 


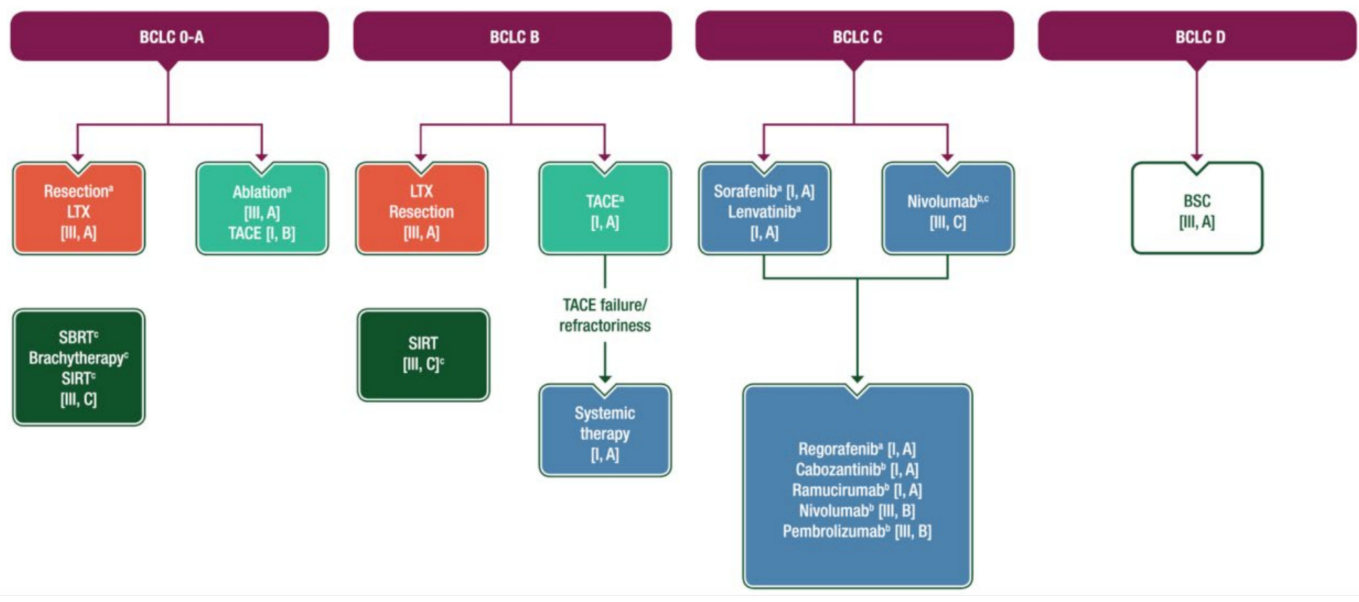

Figure 7. eUpdated European Society of Medical Oncology (ESMO) guideline on hepatocellular carcinoma algorithm on 19 June 2020. Reprinted from Ref. [101]. An Open Access article (CC BY 4.0).

Author Contributions: This review paper was totally written by the author. Author has read and agreed to the published version of the manuscript.

Funding: This paper was written as a review paper. The author received no external funding for the preparation of this paper.

Conflicts of Interest: The author received honoraria (speaker fees) from Eisai, Guerbet, Bayer, MSD, Eli Lilly, Daiichi-Sankyo, Fujiyakuhin, Asahi Intecc, Terumo, Piolax, Philips, and Canon.

\section{References}

1. Yamada, R.; Sato, M.; Kawabata, M.; Nakatsuka, H.; Nakamura, K.; Takashima, S. Hepatic artery embolization in 120 patients with unresectable hepatoma. Radiology 1983, 148, 397-401. [CrossRef] [PubMed]

2. Lo, C.M.; Ngan, H.; Tso, W.K.; Liu, C.L.; Lam, C.M.; Poon, R.T.; Fan, S.T.; Wong, J. Randomized controlled trial of transarterial lipiodol chemoembolization for unresectable hepatocellular carcinoma. Hepatology 2002, 35, 1164-1171. [CrossRef] [PubMed]

3. Llovet, J.M.; Real, M.I.; Montaña, X.; Planas, R.; Coll, S.; Aponte, J.; Ayuso, C.; Sala, M.; Muchart, J.; Solà, R.; et al. Arterial embolisation or chemoembolisation versus symptomatic treatment in patients with unresectable hepatocellular carcinoma: A randomised controlled trial. Lancet 2002, 359, 1734-1739. [CrossRef]

4. Cammà, C.; Schepis, F.; Orlando, A.; Albanese, M.; Shahied, L.; Trevisani, F.; Andreone, P.; Craxì, A.; Cottone, M. Transarterial chemoembolization for unresectable hepatocellular carcinoma: Meta-analysis of randomized controlled trials. Radiology 2002, 224, 47-54. [CrossRef] [PubMed]

5. Marelli, L.; Stigliano, R.; Triantos, C.; Senzolo, M.; Cholongitas, E.; Davies, N.; Tibballs, J.; Meyer, T.; Patch, T.M.; Burroughs, A.K. Transarterial therapy for hepatocellular carcinoma: Which technique is more effective? A systematic review of cohort and randomized studies. Cardiovasc. Intervent. Radiol. 2007, 30, 6-25. [CrossRef]

6. EASL clinical practice guidelines: Management of hepatocellular carcinoma. J. Hepatol. 2018, 69, $182-236$. [CrossRef]

7. Ekataksin, W. The isolated artery: An intrahepatic arterial pathway that can bypass the lobular parenchyma in mammalian livers. Hepatology 2000, 31, 269-279. [CrossRef]

8. Kobayashi, S.; Nakanuma, Y.; Terada, T.; Matsui, O. Postmortem survey of bile duct necrosis and biloma in hepatocellular carcinoma after transcatheter arterial chemoembolization therapy: Relevance to microvascular damages of peribiliary capillary plexus. Am. J. Gastroenterol. 1993, 88, 1410-1415.

9. Kobayashi, S.; Nakamuma, Y.; Matsui, O. Histopathology of portal tracts in livers after transcatheter arterial chemo-embolization therapy for hepatocellular carcinoma. J. Gastroenterol. Hepatol. 1994, 9, 45-54. [CrossRef]

10. Yoshida, K.; Matsui, O.; Miyayama, S.; Ibukuro, K.; Yoneda, N.; Inoue, D.; Kozaka, K.; Minami, T.; Koda, W.; Gabata, T. Isolated arteries originating from the intrahepatic arteries: Anatomy, function, and importance in intervention. J. Vasc. Interv. Radiol. 2018, 29, 531-537.e1. [CrossRef] 
11. Matsuo, N.; Uchida, H.; Nishimine, K.; Soda, S.; Oshima, M.; Nakano, H.; Nagano, N.; Nishimura, Y.; Yoshioka, T.; Guo, Q.; et al. Segmental transcatheter hepatic artery chemoembolization with iodized oil for hepatocellular carcinoma: Antitumor effect and influence on normal tissue. J. Vasc. Interv. Radiol. 1993, 4, 543-549. [CrossRef]

12. Miyayama, S.; Mitsui, T.; Zen, Y.; Sudo, Y.; Yamashiro, M.; Okuda, M.; Yoshie, Y.; Sanada, T.; Notsumata, K.; Tanaka, N.; et al. Histopathological findings after ultraselective transcatheter arterial chemoembolization for hepatocellular carcinoma. Hepatol. Res. 2009, 39, 374-381. [CrossRef] [PubMed]

13. Miyayama, S.; Matsui, O. Superselective conventional transarterial chemoembolization for hepatocellular carcinoma: Rationale, technique, and outcome. J. Vasc. Interv. Radiol. 2016, 27, 1269-1278. [CrossRef]

14. Hayashi, M.; Matsui, O.; Ueda, K.; Kawamori, Y.; Kadoya, M.; Yoshikawa, J.; Gabata, T.; Takashima, T.; Nonomua, A.; Nakanuma, Y. Correlation between the blood supply and grade of malignancy of hepatocellular nodules associated with liver cirrhosis: Evaluation by CT during intraarterial injection of contrast medium. AJR. Am. J. Roentgenol. 1999, 172, 969-976. [CrossRef]

15. Kuroda, C.; Sakurai, M.; Monden, M.; Marukawa, T.; Hosoki, T.; Tokunaga, K.; Wakasa, K.; Okamura, J.; Kozuka, T. Limitation of transcatheter arterial chemoembolization using iodized oil for small hepatocellular carcinoma. A study in resected cases. Cancer 1991, 67, 81-86. [CrossRef]

16. Kitao, A.; Zen, Y.; Matsui, O.; Gabata, T.; Nakanuma, Y. Hepatocarcinogenesis: Multistep changes of drainage vessels at CT during arterial portography and hepatic arteriography-radiologic-pathologic correlation. Radiology 2009, 252, 605-614. [CrossRef]

17. Ueda, K.; Matsui, O.; Kawamori, Y.; Nakamuma, Y.; Kadoya, M.; Yoshikawa, J.; Gabata, T.; Nonomura, A.; Takashima, T. Hypervascular hepatocellular carcinoma: Evaluation of hemodynamics with dynamic CT during hepatic arteriography. Radiology 1998, 206, 161-166. [CrossRef]

18. Goseki, N.; Nosaka, T.; Endo, M.; Koike, M. Nourishment of hepatocellular carcinoma cells through the portal blood flow with and without transcatheter arterial embolization. Cancer 1995, 76, 736-742. [CrossRef]

19. Ekelund, L.; Lin, G.; Jeppsson, B. Blood supply of experimental liver tumors after intraarterial embolization with Gelfoam powder and absolute ethanol. Cardiovasc. Intervent. Radiol. 1984, 7, 234-239. [CrossRef]

20. Kim, B.K.; Kim, S.U.; Kim, K.A.; Chung, Y.E.; Kim, M.J.; Park, M.S.; Park, J.Y.; Kim, D.Y.; Ahn, S.H.; Kim, M.D.; et al. Complete response at first chemoembolization is still the most robust predictor for favorable outcome in hepatocellular carcinoma. J. Hepatol. 2015, 62, 1304-1310. [CrossRef]

21. Kojiro, M.; Sugihara, S.; Kakizoe, S.; Nakashima, O.; Kiyomatsu, K. Hepatocellular carcinoma with sarcomatous change: A special reference to the relationship with anticancer therapy. Cancer Chemother. Pharmacol. 1989, 23, S4-S8. [CrossRef] [PubMed]

22. Zen, C.; Zen, Y.; Mitry, R.R.; Corbeil, D.; Karbanová, J.; O’Gray, J.; Karani, J.; Kane, P.; Heaton, N.; Portmann, B.C.; et al. Mixed phenotype hepatocellular carcinoma after transarterial chemoembolization and liver transplantation. Liver Transpl. 2011, 17, 943-954. [CrossRef] [PubMed]

23. Sergio, A.; Cristofori, C.; Cardin, R.; Pivetta, G.; Ragazzi, R.; Baldan, A.; Girardi, L.; Cillio, U.; Burra, P.; Giacomin, A.; et al. Transcatheter arterial chemoembolization (TACE) in hepatocellular carcinoma (HCC): The role of angiogenesis and invasiveness. Am. J. Gastroenterol. 2008, 103, 914-921. [CrossRef] [PubMed]

24. Wang, B.; Xu, H.; Gao, Z.Q.; Ning, H.F.; Sun, Y.Q.; Cao, G.W. Increased expression of vascular endothelial growth factor in hepatocellular carcinoma after transcatheter arterial chemoembolization. Acta. Radiol. 2008, 49, 523-529. [CrossRef]

25. Miyayama, S.; Matsui, O.; Zen, Y.; Yamashiro, M.; Hattori, Y.; Orito, N.; Matsui, K.; Tsuji, K.; Yoshida, M.; Sudo, Y. Portal blood supply to locally progressed hepatocellular carcinoma after transcatheter arterial chemoembolization: Observation on CT during arterial portography. Hepatol. Res. 2011, 41, 853-866. [CrossRef]

26. Miyayama, S.; Yamashiro, M.; Sugimori, N.; Ikeda, R.; Okimura, K.; Sakuragawa, N. Outcomes of patients with hepatocellular carcinoma treated with conventional transarterial chemoembolization using guidance software. J. Vasc. Interv. Radiol. 2019, 30, 10-18. [CrossRef]

27. Arizumi, T.; Minami, T.; Chishina, H.; Kono, M.; Takita, M.; Yada, N.; Hagiwara, S.; Minami, Y.; Ida, H.; Ueshima, K.; et al. Time to transcatheter arterial chemoembolization refractoriness in patients with hepatocellular carcinoma in Kinki Criteria stages B1 and B2. Dig. Dis. 2017, 35, 589-597. [CrossRef] 
28. Monier, A.; Guiu, B.; Duran, R.; Aho, S.; Bize, P.; Deltenre, P.; Dunet, V.; Denys, A. Liver and biliary damages following transarterial chemoembolization of hepatocellular carcinoma: Comparison between drug-eluting beads and lipiodol emulsion. Eur. Radiol. 2017, 27, 1431-1439. [CrossRef]

29. Namur, J.; Wassef, M.; Millot, J.M.; Lewis, A.L.; Manfait, M.; Laurent, A. Drug-eluting beads for liver embolization: Concentration of doxorubicin in tissue and in beads in a pig model. J. Vasc. Interv. Radiol. 2010, 21, 259-267. [CrossRef]

30. Padia, S.A.; Shivaram, G.; Bastawrous, S.; Bhargava, P.; Vo, N.J.; Vaidya, S.; Valji, K.; Harris, W.P.; Hippe, D.S.; Kogut, M.J. Safety and Efficacy of drug-eluting bead chemoembolization for hepatocellular carcinoma: Comparison of small-versus medium-size particles. J. Vasc. Interv. Radiol. 2013, 24, 301-306. [CrossRef]

31. Brown, K.T. Fatal pulmonary complications after arterial embolization with 40-120- micro m tris-acryl gelatin microspheres. J. Vasc. Interv. Radiol. 2004, 15 Pt 1, 197-200. [CrossRef]

32. Maluccio, M.A.; Covey, A.M.; Porat, L.B.; Schubert, J.; Brody, L.A.; Sofocleoud, C.T.; Getrajdman, G.I.; Jarnagin, W.; Dematteo, R.; Blumgart, L.H.; et al. Transcatheter arterial embolization with only particles for the treatment of unresectable hepatocellular carcinoma. J. Vasc. Interv. Radiol. 2008, 19, 862-869. [CrossRef] [PubMed]

33. Miyayma, S.; Matsui, O. Applying superselective conventional TACE. Endovasc. Today 2017, 16, 52-56.

34. Minamiguchi, K.; Tanaka, T.; Nishiofuku, H.; Fukuoka, Y.; Taiji, R.; Matsumoto, T.; Saito, N.; Taguchi, H.; Marugami, N.; Hirai, T.; et al. Comparison of embolic effect between water-in-oil emulsion and microspheres in transarterial embolization for rat hepatocellular carcinoma model. Hepatol. Res. 2020. Available online: https://pubmed.ncbi.nlm.nih.gov/32822527/ (accessed on 21 August 2020). [CrossRef]

35. Lee, S.; Kim, K.M.; Lee, S.J.; Lee, K.H.; Lee, D.Y.; Kim, M.D.; Kim, D.Y.; Kim, S.U.; Won, J.Y. Hepatic arterial damage after transarterial chemoembolization for the treatment of hepatocellular carcinoma: Comparison of drug-eluting bead and conventional chemoembolization in a retrospective controlled study. Acta. Radiol. 2017, 58, 131-139. [CrossRef]

36. Shimose, S.; Iwamoto, H.; Tanaka, M.; Niizeki, T.; Shirono, T.; Nakano, M.; Okumura, S.; Noda, Y.; Kamachi, N.; Sakai, M.; et al. Increased arterio-portal shunt formation after drug-eluting beads TACE for hepatocellular carcinoma. Oncology 2020, 98, 558-565. [CrossRef]

37. De Baere, T.; Zhang, X.; Aubert, B.; Harry, G.; Lagrange, C.; Ropers, J.; Dufaux, J.; Lumbroso, J.; Rougier, P.; Ducreux, M.; et al. Quantification of tumor uptake of iodized oils and emulsions of iodized oils: Experimental study. Radiology 1996, 201, 731-735. [CrossRef]

38. Demachi, H.; Matsui, O.; Abo, H.; Tatsu, H. Simulation model based on non-Newtonian fluid mechanics applied to the evaluation of the embolic effect of emulsions of iodized oil and anticancer drug. Cardiovasc. Intervent. Radiol. 2000, 23, 285-290. [CrossRef] [PubMed]

39. Terayama, N.; Matsui, O.; Gabata, T.; Kobayashi, S.; Sanada, J.; Ueda, K.; Kadoya, M.; Kawamori, Y. Accumulation of iodized oil within the nonneoplastic liver adjacent to hepatocellular carcinoma via the drainage routes of the tumor after transcatheter arterial embolization. Cardiovasc. Intervent. Radiol. 2001, 24, 383-387. [CrossRef]

40. Miyayama, S.; Matsui, O.; Yamashiro, M.; Ryu, Y.; Kaito, K.; Ozaki, K.; Takeda, T.; Yoneda, N.; Notsumata, K.; Toya, D.; et al. Ultraselective transcatheter arterial chemoembolization with a 2-F tip microcatheter for small hepatocellular carcinomas: Relationship between local tumor recurrence and visualization of the portal vein with iodized oil. J. Vasc. Interv. Radiol. 2007, 18, 365-376. [CrossRef]

41. Miyayama, S.; Yamashiro, M.; Okuda, M.; Abrano, H.; Shigenari, N.; Morinaga, K.; Matsui, O. Anastomosis between the hepatic artery and the extrahepatic collateral or between extrahepatic collaterals: Observation on angiography. J. Med. Imag. Radiat. Oncol. 2009, 53, 271-282. [CrossRef] [PubMed]

42. Irie, T.; Kuramochi, M.; Takahashi, N. Diameter of main tumor feeding artery of a hepatocellular carcinoma: Measurement at the entry site into the nodule. Hepatol. Res. 2016, 46, E100-E104. [CrossRef] [PubMed]

43. Iwamoto, S.; Yamaguchi, T.; Hongo, O.; Iwamoto, H.; Sanefuji, H. Excellent outcomes with angiographic subsegmentectomy in the treatment of typical hepatocellular carcinoma. A retrospective study of local recurrence and long-term survival rates in 120 patients with hepatocellular carcinoma. Cancer 2010, 116, 393-399. [CrossRef] [PubMed]

44. De Baere, T.; Arai, Y.; Lencioni, R.; Geschwind, J.F.; Rilling, W.; Salem, R.; Matsui, O.; Soulen, M.C. Treatment of liver tumors with Lipiodol TACE: Technical recommendations from experts opinion. Cardiovasc. Intervent. Radiol. 2016, 239, 334-343. [CrossRef] 
45. Malagari, K.; Pomoni, M.; Kelekis, A.; Pomoni, A.; Dourakis, S.; Spyridopoulos, T.; Moschouris, H.; Emmanouil, E.; Rizos, S.; Kelekis, D. Prospective randomized comparison of chemoembolization with doxorubicin-eluting beads and bland embolization with BeadBlock for hepatocellular carcinoma. Cardiovasc. Intervent. Radiol. 2010, 33, 541-551. [CrossRef] [PubMed]

46. Brown, K.T.; Do, R.K.; Gonen, M.; Covey, A.M.; Getrajdman, G.I.; Sofocleous, C.T.; Jarnagin, W.R.; D'Angelica, M.I.; Allen, P.J.; Erinjeri, J.P.; et al. Randomized trial of hepatic artery embolization for hepatocellular carcinoma using doxorubicin-eluting microspheres compared with embolization with microspheres alone. J. Clin. Oncol. 2016, 34, 2046-2053. [CrossRef]

47. Osuga, K.; Khankan, A.A.; Hori, S.; Okada, A.; Sugiura, T.; Maeda, M.; Nagano, H.; Yamada, A.; Murakami, T.; Nakamura, H. Transarterial embolization for large hepatocellular carcinoma with use of superabsorbent polymer microspheres: Initial experience. J. Vasc. Interv. Radiol. 2002, 13 Pt 1, 929-934. [CrossRef]

48. Osuga, K.; Hori, S.; Hiraishi, K.; Sugiura, T.; Hata, Y.; Higashihara, H.; Maeda, N.; Tomoda, K.; Nakamura, N. Bland embolization of hepatocellular carcinoma using superabsorbent polymer microspheres. Cardiovasc. Intervent. Radiol. 2008, 31, 1108-1116. [CrossRef]

49. Lanza, E.; Muglia, R.; Bolengo, I.; Poretti, D.; D’Antuono, F.; Ceriani, R.; Torzilli, G.; Pedicini, V. Survival analysis of 230 patients with unresectable hepatocellular carcinoma treated with bland transarterial embolization. PLOS ONE 2020, 15, e0227711. [CrossRef]

50. Kung, C.T.; Liu, B.M.; Ng, S.H.; Lee, T.Y.; Cheng, Y.F.; Chen, M.C.; Ko, S.F. Transcatheter arterial embolization in the emergency department for hemodynamic instability due to ruptured hepatocellular carcinoma: Analysis of 167 cases. AJR. Am. J. Roentgenol. 2008, 191, W231-W239. [CrossRef]

51. Kamada, K.; Nakanishi, T.; Kitamoto, M.; Aikata, H.; Kawakami, Y.; Ito, K.; Kajiyama, G. Long-term prognosis of patients undergoing transcatheter arterial chemoembolization for unresectable hepatocellular carcinoma: Comparison of cisplatin lipiodol suspension and doxorubicin hydrochloride emulsion. J. Vasc. Interv. Radiol. 2001, 12, 847-854. [CrossRef]

52. Yodono, H.; Matsuo, K.; Shinohara, A. A retrospective comparative study of epirubicin-lipiodol emulsion and cisplatin-lipiodol suspension for use with transcatheter arterial chemoembolization. Anticancer Drugs 2011, 22, 277-282. [CrossRef]

53. Kasai, K.; Ushio, A.; Sawara, K.; Miyamoto, Y.; Kasai, Y.; Oikawa, K.; Kuroda, H.; Takikawa, Y.; Suzuki, K. Transcatheter arterial chemoembolization with a fine-powder formulation of cisplatin for hepatocellular carcinoma. World J. Gastroenterol. 2010, 16, 3437-3444. [CrossRef] [PubMed]

54. Sahara, S.; Kawai, N.; Sato, M.; Minamiguchi, H.; Nakai, M.; Takasaka, I.; Nakata, K.; Ikoma, A.; Sawa, N.; Sonomura, T.; et al. Prospective comparison of transcatheter arterial chemoembolization with Lipiodol-epirubicin and Lipiodol-cisplatin for treatment of recurrent hepatocellular carcinoma. Jpn. J. Radiol. 2010, 28, 362-368. [CrossRef]

55. Kawaoka, T.; Aikata, H.; Katamura, Y.; Takaki, S.; Waki, K.; Hiramatsu, A.; Takahashi, S.; Hieda, M.; Kakizawa, H.; Chayama, K. Hypersensitivity reactions to transcatheter chemoembolization with cisplatin and Lipiodol suspension for unresectable hepatocellular carcinoma. J. Vasc. Interv. Radiol. 2010, 21, 1219-1225. [CrossRef] [PubMed]

56. Maeda, N.; Osuga, K.; Higashihara, H.; Tomoda, K.; Mikami, K.; Nakazawa, T.; Nakamura, H.; Tomiyama, N. Transarterial chemoembolization with cisplatin as second-line treatment for hepatocellular carcinoma unresponsive to chemoembolization with epirubicin-Lipiodol emulsion. Cardiovasc. Intervent. Radiol. 2012, 35, 82-89. [CrossRef] [PubMed]

57. Ikeda, M.; Kudo, M.; Aikata, H.; Nagamatsu, H.; Ishii, H.; Yokosuka, O.; Torimura, T.; Morimoto, M.; Ikeda, K.; Kumada, H.; et al. Transarterial chemoembolization with miriplatin vs. epirubicin for unresectable hepatocellular carcinoma: A phase III randomized trial. J. Gastroenterol. 2018, 53, 281-290. [CrossRef]

58. Miyayama, S.; Yamashiro, M.; Shibata, Y.; Hashimoto, M.; Yoshida, M.; Tsuji, K.; Toshima, F.; Matsui, O. Comparison of local control effects of superselective transcatheter arterial chemoembolization using epirubicin plus mitomycin C and miriplatin for hepatocellular carcinoma. Jpn. J. Radiol. 2012, 30, 263-270. [CrossRef]

59. Iwazawa, J.; Ohue, S.; Hashimoto, N.; Mitani, T. Local tumor progression following lipiodol-based targeted chemoembolization of hepatocellular carcinoma: A retrospective comparison of miriplatin and epirubicin. Cancer Manag. Res. 2012, 4, 113-119. [CrossRef] 
60. Irie, T.; Kuramochi, M.; Takahashi, N. Dense accumulation of Lipiodol emulsion in hepatocellular carcinoma nodule during selective balloon-occluded transarterial chemoembolization: Measurement of balloon occluded arterial stump pressure. Cardiovasc. Intervent. Radiol. 2013, 36, 706-713. [CrossRef]

61. Maeda, N.; Osuga, K.; Higashihara, H.; Mikami, K.; Tomoda, K.; Hori, S.; Nakazawa, T.; Nakamura, H. In vitro characterization of cisplatin-loaded superabsorbent polymer microspheres designed for chemoembolization. J. Vasc. Interv. Radiol. 2010, 21, 877-881. [CrossRef] [PubMed]

62. Lammer, J.; Malagari, K.; Vogl, T.; Pilleul, F.; Denys, A.; Watkinson, A.; Pitton, M.; Sergent, G.; Pfammatter, T.; Terraz, S.; et al. Prospective randomized study of doxorubicin-eluting-bead embolization in the treatment of hepatocellular carcinoma: Results of the PRECISION V study. Cardiovasc. Intervent. Radiol. 2010, 33, 41-52. [CrossRef] [PubMed]

63. Sacco, R.; Bargellini, I.; Bertini, M.; Bozzi, E.; Romano, A.; Petruzzi, P.; Tumino, E.; Gianni, B.; Federici, G.; Cioni, R.; et al. Conventional versus doxorubicin-eluting bead transarterial chemoembolization for hepatocellular carcinoma. J. Vasc. Interv. Radiol. 2011, 22, 1545-1552. [CrossRef] [PubMed]

64. Golifieri, R.; Giampalma, E.; Renzulli, M.; Cioni, R.; Bargellini, I.; Bartolozzi, C.; Breatta, A.D.; Gandini, G.; Nani, R.; Gasparini, D.; et al. Randomised controlled trial of doxorubicin-eluting beads vs conventional chemoembolisation for hepatocellular carcinoma. Br. J. Cancer 2014, 111, 255-264. [CrossRef]

65. Ikeda, M.; Inaba, Y.; Tanaka, T.; Sugawara, S.; Kodama, Y.; Aramaki, T.; Anai, H.; Morita, S.; Tsukahara, Y.; Seki, H.; et al. A prospective, randomized, controlled trial of selective DEB-TACE vs. selective cTACE with epirubicinfor hepatocellular carcinoma: JIVROSG-1302 PRESIDENT study. J. Clin. Oncol. 2020, 38. (suppl; abstr 4518). [CrossRef]

66. Ishikura, H.; Sotozaki, Y.; Adachi, H.; Sato, M.; Yoshiki, T. Granulomatous arteritis with massive eosinophilic leukocyte infiltration and transient peripheral eosinophilia subsequent to transarterial embolization therapy with a gelatin sponge. Acta. Pathol. Jpn. 1991, 41, 618-622. [CrossRef]

67. Miyayama, S.; Yanakado, K.; Anai, H.; Abo, D.; Minami, T.; Takaki, H.; Kodama, T.; Yamanaka, T.; Nishiofuku, H.; Morimoto, K.; et al. Guidelines on the use of gelatin sponge particles in embolotherapy. Jpn. J. Radiol. 2014, 32, 242-250. [CrossRef]

68. Kim, H.C.; Chung, J.W.; Lee, W.; Jae, H.J.; Park, J.H. Recognizing extrahepatic collateral vessels that supply hepatocellular carcinoma to avoid complications of transcatheter arterial chemoembolization. Radiographics 2005, 25 (Suppl. S1), S25-S39. [CrossRef]

69. Miyayama, S.; Matsui, O.; Taki, K.; Minami, T.; Ryu, Y.; Ito, C.; Nakamura, K.; Inoue, D.; Notsumata, K.; Toya, D.; et al. Extrahepatic blood supply to hepatocellular carcinoma: Angiographic demonstration and transcatheter arterial chemoembolization. Cardiovasc. Intervent. Radiol. 2006, 29, 39-48. [CrossRef]

70. Sakon, M.; Nagano, H.; Nakamori, S.; Dono, K.; Ueshita, K.; Murakami, T.; Nakamura, H.; Monden, M. Intrahepatic recurrences of hepatocellular carcinoma after hepatectomy: Analysis based on tumor hemodynamics. Arch. Surg. 2002, 137, 94-99. [CrossRef]

71. Miyayama, S.; Yamashiro, M.; Hashimoto, M.; Hashimoto, N.; Ikuno, M.; Okumura, K.; Yoshida, M.; Matsui, O. Comparison of local control in transcatheter arterial chemoembolization of hepatocellular carcinoma $\leq 6 \mathrm{~cm}$ with or without intraprocedural monitoring of the embolized area using cone-beam computed tomography. Cardiovasc. Intervent. Radiol. 2014, 37, 388-395. [CrossRef] [PubMed]

72. Miyayama, S.; Yamashiro, M.; Ikuno, M.; Okumura, K.; Yoshida, M. Ultraselective transcatheter arterial chemoembolization for small hepatocellular carcinoma guided by automated tumor-feeders detection software: Technical success and short-term tumor response. Abdom. Imaging 2014, 39, 645-656. [CrossRef] [PubMed]

73. Sasaki, A.; Kai, S.; Iwashita, Y.; Hirano, S.; Ohta, M.; Kitano, S. Microsatellite distribution and indication for locoregional therapy in small hepatocellular carcinoma. Cancer 2005, 103, 299-306. [CrossRef] [PubMed]

74. Miyayama, S. Ultraselective conventional transarterial chemoembolization: When and how? Clin. Mol. Hepatol. 2019, 25, 344-353. [CrossRef]

75. Takeuchi, Y.; Arai, Y.; Inaba, Y.; Ohno, K.; Maeda, T.; Itai, Y. Extrahepatic arterial supply to the liver: Observation with a unified CT and angiography system during temporary balloon occlusion of the proper hepatic artery. Radiology 1998, 209, 121-128. [CrossRef]

76. Mok, K.T.; Wang, B.W.; Lo, G.H.; Liang, H.L.; Liu, S.I.; Chou, N.H.; Tsai, C.C.; Chen, I.S.; Yeh, M.H.; Chen, Y.C. Multimodality management of hepatocellular carcinoma larger than $10 \mathrm{~cm}$. J. Am. Coll. Surg. 2003, 197, 730-738. [CrossRef] 
77. Huang, Y.H.; Wu, J.C.; Chen, S.C.; Chen, C.H.; Chiang, J.H.; Huo, T.I.; Lee, P.C.; Chang, F.Y.; Lee, S.D. Survival benefit of transcatheter arterial chemoembolization in patients with hepatocellular carcinoma larger than $10 \mathrm{~cm}$ in diameter. Aliment. Pharmacol. Ther. 2006, 23, 129-135. [CrossRef]

78. Chung, J.W.; Park, J.H.; Im, J.G.; Han, J.K.; Han, M.C. Pulmonary oil embolism after transcatheter oily chemoembolization of hepatocellular carcinoma. Radiology 1993, 187, 689-693. [CrossRef]

79. Li, Z.; Ni, R.F.; Busireddy, K.K.; Jin, Y.H.; Zhao, X.; Li, M.M.; Yang, C. Cerebral lipiodol embolism following transcatheter arterial chemoembolization for hepatocellular carcinoma: A report of two cases and literature review. Chin. Med. J. 2011, 124, 4355-4358.

80. Sakamoto, N.; Monzawa, S.; Nagano, H.; Nishizaki, H.; Arai, Y.; Sugimura, K. Acute tumor lysis syndrome caused by transcatheter oily chemoembolization in a patient with a large hepatocellular carcinoma. Cardiovasc. Intervent. Radiol. 2007, 30, 508-511. [CrossRef]

81. Miyayama, S.; Yamashiro, M.; Okuda, M.; Yoshie, Y.; Sugimori, N.; Igarashi, S.; Nakashima, Y.; Notsumata, K.; Toya, D.; Tanaka, N.; et al. Chemoembolization for the treatment of large hepatocellular carcinoma. J. Vasc. Interv. Radiol. 2010, 21, 1226-1234. [CrossRef] [PubMed]

82. Miyayama, S.; Kikuchi, Y.; Yoshida, M.; Yamashiro, M.; Sugimori, N.; Ikeda, R.; Okimura, K.; Sakuragawa, N.; Ueda, T.; Sanada, T.; et al. Outcomes of conventional transarterial chemoembolization for hepatocellular carcinoma $\geq 10 \mathrm{~cm}$. Hepatol. Res. 2019, 49, 787-798. [CrossRef] [PubMed]

83. Hidaka, T.; Anai, H.; Sakaguchi, H.; Sueyoshi, S.; Tanaka, T.; Yamamoto, K.; Morimoto, K.; Nishiofuku, H.; Maeda, S.; Nagata, T.; et al. Efficacy of combined bland embolization and chemoembolization for huge $(\geq 10 \mathrm{~cm})$ hepatocellular carcinoma. Minim. Invasive Ther. Allied. Technol. 2020. Available online: https://pubmed.ncbi.nlm.nih.gov/32031474/ (accessed on 7 February 2020). [CrossRef]

84. Takayasu, K.; Muramatsu, Y.; Maeda, T.; Iwata, R.; Furukawa, H.; Muramatsu, Y.; Moriyama, N.; Okusaka, T.; Okada, S.; Ueno, H. Targeted transarterial oily chemoembolization for small foci of hepatocellular carcinoma using a unified helical CT and angiography system: Analysis of factors affecting local recurrence and survival rates. AJR. Am. J. Roentogenol. 2001, 176, 681-688. [CrossRef] [PubMed]

85. Iwazawa, J.; Ohue, S.; Hashimoto, N.; Muramoto, O.; Mitani, T. Survival after C-arm CT-assisted chemoembolization of unresectable hepatocellular carcinoma. Eur. J. Radiol. 2012, 81, 3985-3992. [CrossRef]

86. Deschamps, F.; Solomon, S.B.; Thornton, R.H.; Rao, P.; Hakime, A.; Kuoch, V.; De Baere, T. Computed analysis of three-dimensional cone-beam computed tomography angiography for determination of tumor-feeding vessels during chemoembolization of liver tumor: A pilot study. Cardiovasc. Intervent. Radiol. 2010, 33, 1235-1242. [CrossRef]

87. Iwazawa, J.; Ohue, S.; Hashimoto, N.; Muramoto, O.; Mitani, T. Clinical utility and limitations of tumor-feeder detection software for liver cancer embolization. Eur. J. Radiol. 2013, 82, 1665-1672. [CrossRef]

88. Miyayama, S.; Yamashiro, M.; Hashimoto, M.; Hashimoto, N.; Ikuno, M.; Okumura, K.; Yoshida, M.; Matsui, O. Identification of small hepatocellular carcinoma and tumor-feeding branches with cone-beam CT guidance technology during transcatheter arterial chemoembolization. J. Vasc. Interv. Radiol. 2013, 24, 501-508. [CrossRef]

89. Minami, Y.; Yagyu, Y.; Murakami, T.; Kudo, M. Tracking navigation imaging of transcatheter arterial chemoembolization for hepatocellular carcinoma using three-dimensional cone-beam CT angiography. Liver Cancer 2014, 3, 53-61. [CrossRef]

90. Miyayama, S.; Yamashiro, M.; Nagai, K.; Tohyama, J.; Kawamura, K. Efficacy of automated tumor-feeder detection software using cone-beam computed tomography technology in transarterial targeted therapy. Intervent. Radiol. 2016, 1, 28-38. [CrossRef]

91. Miyayama, S.; Yamashiro, M.; Nagai, K.; Tohyama, J.; Kawamura, K.; Yoshida, M.; Sakuragawa, N. Efficacy of automated tumor-feeder detection software using cone-beamcomputed tomography technology in transarterial embolization through extrahepatic collateral vessels for malignant hepatic tumors. Hepatol. Res. 2016, 46, 166-173. [CrossRef]

92. Kudo, M.; Han, K.H.; Ye, S.L.; Zhou, J.; Huang, Y.H.; Lin, S.M.; Wang, C.K.; Ikeda, M.; Chan, S.T.; Choo, S.P.; et al. A changing paradigm for the treatment of intermediate-stage hepatocellular carcinoma: Asia-Pacific Primary Liver Cancer Expert Consensus Statements. Liver Cancer 2020, 9, 245-260. [CrossRef] [PubMed] 
93. Saito, N.; Tanaka, T.; Nishiofuku, H.; Sato, T.; Masada, T.; Matsumoto, T.; Anai, H.; Sakaguchi, H.; Sueyoshi, S.; Marugami, N.; et al. Transarterial chemoembolization remains an effective therapy for intermediate-stage hepatocellular carcinoma with preserved liver function. Hepatol. Res. 2020. Available online: https: //pubmed.ncbi.nlm.nih.gov/32721060/ (accessed on 28 July 2020). [CrossRef]

94. Jain, R.K. Normalization of tumor vasculature: An emerging concept in antiangiogenic treatment. Science 2005, 307, 58-62. [CrossRef]

95. Kano, M.R.; Komuta, Y.; Iwata, C.; Oka, M.; Shirai, Y.; Morishita, Y.; Ouchi, Y.; Kataoka, K.; Miyazono, K. Comparison of the effects of the kinase inhibitors imatinib, sorafenib, and transforming growth factor-beta receptor inhibitor on extravasation of nanoparticles from neovasculature. Cancer Sci. 2009, 100, 173-180. [CrossRef]

96. Yamakado, K.; Miyayama, S.; Hirota, S.; Mizunuma, K.; Nakamura, K.; Inaba, Y.; Maeda, H.; Matsuo, K.; Nishida, N.; Aramaki, T.; et al. Subgrouping of intermediate-stage (BCLC stage B) hepatocellular carcinoma based on tumor number and size and Child-Pugh grade correlated with prognosis after transarterial chemoembolization. Jpn. J. Radiol. 2014, 32, 260-265. [CrossRef]

97. Yamakado, K.; Miyayama, S.; Hirota, S.; Mizunuma, K.; Nakamura, K.; Inaba, Y.; Maeda, H.; Matsuo, K.; Nishida, N.; Aramaki, T.; et al. Prognosis of patients with intermediate-stage hepatocellular carcinomas based on the Child-Pugh score: Subclassifying the intermediate stage (Barcelona Clinic Liver Cancer Stage B). Jpn. J. Radiol. 2014, 32, 644-649. [CrossRef]

98. Yamakado, K.; Miyayama, S.; Hirota, S.; Mizunuma, K.; Nakamura, K.; Inaba, Y.; Maeda, H.; Matsuo, K.; Nishida, N.; Aramaki, T.; et al. Hepatic arterial embolization for unresectable hepatocellular carcinomas: Do technical factors affect prognosis? Jpn. J. Radiol. 2012, 30, 560-566. [CrossRef]

99. Duffy, A.; Wilkerson, J.; Greten, T.F. Hemorrhagic events in hepatocellular carcinoma patients treated with antiangiogenic therapies. Hepatology 2013, 57, 1068-1077. [CrossRef]

100. Miyayama, S.; Matsui, O.; Yamashiro, M.; Ryu, Y.; Takata, H.; Takeda, T.; Aburano, H.; Shigenari, N. Iodized oil accumulation in the hypovascular tumor portion of early-stage hepatocellular carcinoma after ultraselective transcatheter arterial chemoembolization. Hepatol. Int. 2007, 1, 451-459. [CrossRef] [PubMed]

101. ESMO Guidelines Committee. eUpdate Hepatocellular Carcinoma Algorithm. Available online: https://www.esmo.org/guidelines/gastrointestinal-cancers/hepatocellular-carcinoma/eupdatehepatocellular-carcinoma-algorithm (accessed on 19 June 2020).

102. Sato, Y.; Nishiofuku, H.; Yasumoto, T.; Nakatsuka, A.; Matsuo, K.; Kodama, Y.; Okubo, H.; Abo, D.; Takaki, H.; Inaba, Y.; et al. Multicenter phase II clinical trial of sorafenib with transarterial chemoembolization for advanced stage hepatocellular carcinomas (Barcelona Clinic Liver Cancer stage C): STAB Study. J. Vasc. Interv. Radiol. 2018, 29, 1061-1067. [CrossRef] [PubMed]

103. Kokudo, N.; Takemura, N.; Hasegawa, K.; Takayama, T.; Kubo, S.; Shimada, M.; Nagano, H.; Hatano, E.; Izumi, N.; Kaneko, S.; et al. Clinical practice guidelines for hepatocellular carcinoma: The Japan Society of Hepatology 2017 (4th JSH-HCC guidelines) 2019 update. Hepatol. Res. 2019, 49, 1109-1113. [CrossRef] [PubMed]

Publisher's Note: MDPI stays neutral with regard to jurisdictional claims in published maps and institutional affiliations.

(C) 2020 by the author. Licensee MDPI, Basel, Switzerland. This article is an open access article distributed under the terms and conditions of the Creative Commons Attribution (CC BY) license (http://creativecommons.org/licenses/by/4.0/). 